\title{
Peningkatan Layan Daya Tampung Pelabuhan Perikanan Wilayah I Pantai Carocok Tarusan
}

\author{
Ahmad Refi \\ Jurusan Teknik Sipil, Institut Teknologi Padang \\ Email: refi_ahmad10@yahoo.com \\ DOI: http://dx.doi.org/10.31869/rtj.v3i2.1848
}

\begin{abstract}
Abstrak: Wilayah Perairan Koto XI Tarusanp Provinsi Sumatera Barat merupakan basis operasi berlabunya kapal-kapal ikan bagi para nelayan. Kondisi perairan Koto XI Tarusan di wilayah Teluk Carocok Anau sangat ideal sekali dijadikan sebagai area pelabuhan karena kondisinya yang terletak di teluk. Menurut data buku laporan tahunan Pelabuhan Pantai Carocok Tarusan armada penangkapan ikan yang berdomisili di Pelabuhan Pantai Carocok Tarusan sebanyak 139 unit,belum termasuk kapal yang dari Kecamatan lain di pesisir selatan, maka seiring meningkatnya tingkat kedatangan kapal maka pelayanan dan pasilitas harus juga di tingkatkan.Untuk memenuhi kebutuhan pelayanan Pelabuhan Perikanan yang harusdisesuai dengan karakteristik berdasarkan Peraturan Menteri KP No.16 Tahun 2004 tentang persyaratan Pelabuhan Perikanan Pantai Carocok Tarusan masih ada kekurangan yang dimiliki yaitu seperti luas lahan yang masih belum terpenuhi. Hasil analisa terhadap kapasitas pengembangan dermaga pelabuhan adalah bahwa panjang dermaga efektif saat ini $100 \mathrm{~m}$ sedangkan total panjang dermaga yang harus disediakan berdasarkan volume peningkatan kunjungan kapal adalah $160 \mathrm{~m}$ dengan estimasi 5\% pada tahun 2024. Jadi untuk panjang dermaga yzng layak untuk digunakan tetapi untuk syarat pelabuhan perikanan menurut peraturan menteri harus ditambah sepanjang $60 \mathrm{~m}$. Untuk luas kolam perlu penambahan sebesar 56,232 Ha. Dan untuk pelayanan dermaga perlu ditingkatkan kembali agar tingkat kedatangan kapal tidak menurun pada periode berikutnya.
\end{abstract}

Kata Kunci : daya tampung , bongkar muat, produksi ikan

\section{PENDAHULUAN}

Di Sumatera Barat wilayah Perairan Koto XI Tarusan merupakan basis operasi pendaratan kapal-kapal ikan bagi para nelayan. Kondisi perairan Koto XI Tarusan di wilayah Teluk Carocok Anau sangat ideal sekali dijadikan sebagai area pelabuhan karena kondisinya yang terletak di teluk.

Menurut data buku laporan tahunan Pelabuhan Pantai Carocok Tarusan armada penangkapan ikan yang berdomisili di Pelabuhan Pantai Carocok Tarusan sebanyak 139 unit,belum termasuk kapal yang dari Kecamatan lain di pesisir selatan, maka seiring meningkatnya tingkat kedatangan kapal maka pelayanan dan pasilitas harus juga di tingkatkan.

Seluruh kegiatan baik yang dilakukan oleh kapal kecil maupun kapal besar membutuhkan adanya titik tambatan atau pemberhentian berupa pelabuhan penampung hasil dan penyebarannya. Menurut Keputusan Menteri Kelautan Dan Perikanan No.65 Tahun 2018 Pelabuhan Perikanan Pantai Carocok Tarusan sudah di tetapkan sebagai pangkalan pendaratan ikan. Untuk itu lokasi Teluk Carocok Anau yang strategis sangat diperlukan terkait peran sebagai interface dalam sistem angkutan ikan ini. Menurut 1Baheramsyah(2012), mengatakan dalam pembangunan dan pengembangan pelabuhan perikanan, harus senantiasa melewati 3 tahap yaitu tahap perencanan (study, investigasi, detail design).Sedangkan menurut 2Ade Marnila(2007), mengatakan bahwa diperlukan penambahan panjang dermaga kapal bongkar dan muat ikan untuk periode 5 tahun kedepan. Pembangunan dan pengembangan pelabuhan perikanan tersebut sebagai upaya untuk menciptakan pusat-pusat pertumbuhan ekonomi yang bertumpu pada komoditas kelautan dan perikanan. Selain untuk mewujudkan implementasi dari Peraturan Presiden No.26/2012 terkait tentang pengembangan sistem logistik nasionalserta mengujudkan Program Peningkatan Kehidupan Nelayan (PKN) yang sebelumnya telah di tetapkan oleh Kepres Nomor 10 tahun 2011.

Untuk memenuhi kebutuhan pelayanan Pelabuhan Perikanan yang harusdisesuai dengan karakteristik berdasarkan Peraturan Menteri KP No.16 Tahun 2004 tentang

$\begin{array}{lll}\text { ISSN 2599-2081 } & \text { Fakultas Teknik UMSB } & 287\end{array}$

EISSN 2599-2090 
persyaratan Pelabuhan Perikanan Pantai Carocok Tarusan masih ada kekurangan yang dimiliki yaitu seperti luas lahan yang masih belum terpenuhi.

Peranan UPTD Pelabuhan Perikanan Wilayah I PantaiCarocok Tarusan diharapkan dapat memfasilitasi kegiatan bongkar muat kapal yang bertambat, tempat beristirahatnya kapal yang melakukan pemberhentian, usaha penangkapan ikan, pusat pemasaran dan pembinaan mutu hasil perikanan, pusat pengembangan masyarakat nelayan, pusat penyuluhan dan pusat informasi, dan juga sebagai tempat menampungnya ikan-ikan.

Selain itu dalam rangka menjadikan Sumatera Barat sebagai pusat pengembangan penangkapan tuna dibagian barat Indonesia di butuhkan dermaga yang layak dan mencukupi untuk melakukan bongkar muat yang sesuai dengan Peraturan Menteri Kelautan danPerikanan.

\section{METODE PENELITIAN}

Secara umum tahapan penelitian dapat dilihat pada Gambar berikut.

\section{Analisa Kesesuaian Karakteristik PPP Carocok Tarusan}

Berdasarkan Peraturan Menteri No.16 Tahun 2004, tentang karakteristik kelas pelabuhan perikanan, Pelabuhan PantaiCarocok Tarusanharus memenuhi persyaratan seperti

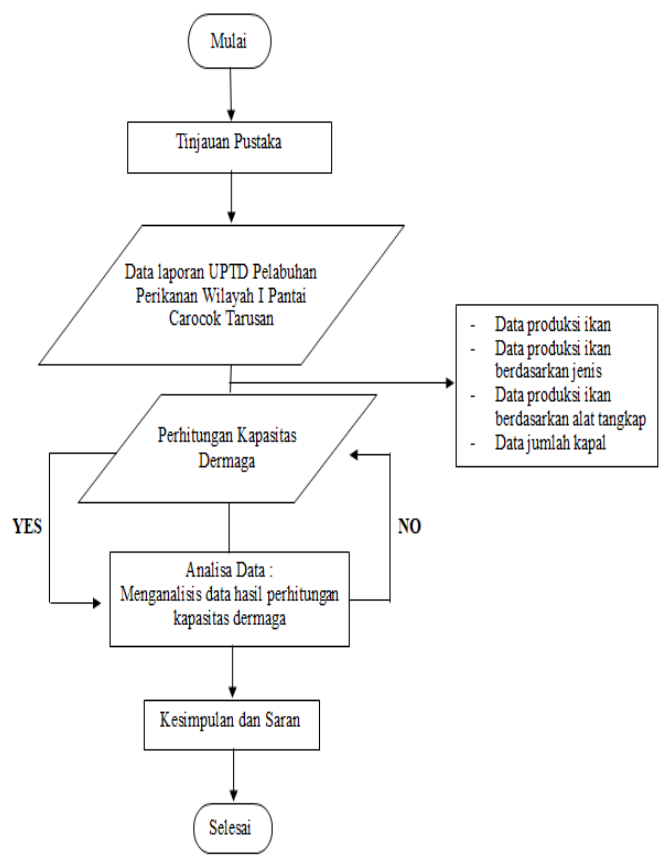

Tabel 1. Analisis kesesuaian karakteristik Pelabuhan Pantai Carocok Tarusanberdasarkan Peraturan Menteri KP No.16 Tahun 2004 tentang persyaratan Pelabuhan Pantai Carocok Tarusan.

\begin{tabular}{|c|c|c|c|c|}
\hline No & $\begin{array}{c}\text { KRITERI } \\
\text { A } \\
\text { PELABUH } \\
\text { AN } \\
\text { PERIKAN } \\
\text { AN }\end{array}$ & $\begin{array}{c}\text { PERSYAR } \\
\text { ATAN } \\
\text { PERMEN } \\
\text { KP NO 16 } \\
\text { TH } 2004\end{array}$ & $\begin{array}{c}\text { KONDI } \\
\text { SI PPP } \\
\text { CT }\end{array}$ & $\begin{array}{l}\text { KETER } \\
\text { ANGAN }\end{array}$ \\
\hline 1. & $\begin{array}{l}\text { Daerah } \\
\text { Operasional } \\
\text { Kapal Ikan } \\
\text { yang } \\
\text { dilayani }\end{array}$ & $\begin{array}{ll}\text { Wilayah } \\
\text { laut } \\
\text { territorial } \\
\text { Zona } \\
\text { Ekonomi } \\
\text { Ekslusif } \\
\text { (ZEE) }\end{array}$ & \begin{tabular}{|ll} 
& Wila \\
yah \\
laut \\
territ \\
orial \\
O Zona \\
Ekon \\
omi \\
Ekslu \\
sif \\
(ZEE \\
)
\end{tabular} & ***** \\
\hline 2. & $\begin{array}{l}\text { Fasilitas } \\
\text { Tambat } \\
\text { Labuh } \\
\text { Kapal }\end{array}$ & $10-30 \mathrm{GT}$ & Ada & \\
\hline 3. & $\begin{array}{l}\text { Panjang } \\
\text { Dermaga }\end{array}$ & $\begin{array}{l}100-150 \\
m\end{array}$ & $100 \mathrm{~m}$ & $\begin{array}{l}\text { Sudah } \\
\text { terpenuhi }\end{array}$ \\
\hline 4. & Kedalaman & $>2 \mathrm{~m}$ & $8 \mathrm{~m}$ & \\
\hline 5. & $\begin{array}{l}\text { Kepastian } \\
\text { Menampun } \\
\text { g Kapal } \\
>10 \mathrm{GT}\end{array}$ & $\begin{array}{l}\text { Menampun } \\
\text { g } 30 \text { buah } \\
\text { kapal } \\
\text { berukuran } \\
10 \mathrm{GT}\end{array}$ & Ada & $\begin{array}{l}\text { Sudah } \\
\text { terpenuhi }\end{array}$ \\
\hline 6. & $\begin{array}{l}\text { Volume } \\
\text { ikan yang } \\
\text { didaratkan }\end{array}$ & - & - & - \\
\hline 7. & Ekport ikan & Tidak & $\begin{array}{l}\text { Tid } \\
\text { ak }\end{array}$ & \\
\hline 8. & Luas lahan & $5-15 \mathrm{Ha}$ & \begin{tabular}{|ll}
$\circ$ & 2, \\
& 19 \\
& Ha \\
& A \\
& da
\end{tabular} & $\begin{array}{l}\text { Belum } \\
\text { terpenuhi }\end{array}$ \\
\hline 9. & $\begin{array}{l}\text { Fasilitas } \\
\text { pembinaan } \\
\text { mutu hasil } \\
\text { perikanan }\end{array}$ & Tidak & - & - \\
\hline
\end{tabular}

terlihat pada Tabel 1 berikut. 


\begin{tabular}{|l|l|l|l|l|}
\hline 10. & $\begin{array}{l}\text { Tata ruang } \\
\text { (zonasi) }\end{array}$ & Ada & Ada & Ada \\
& Pengolahan & & & \\
& $/$ \\
& Pengemban & & & \\
gan Industri & & & \\
& Perikanan & & & \\
\hline
\end{tabular}

( Sumber : Pelabuhan Perikanan

PantaiCarocok Tarusan)

Tabel 1. menunjukkan bahwa kondisi Pelabuhan Perikanan PantaiCarocok Tarusansaat ini, ternyata sudah memenuhi persyaratan sebagai Pelabuhan PantaiCarocok Tarusan.

\section{Kondisi Geografis}

Pelabuhan Perikanan PantaiCarocok Tarusan(PPPCT) berada dalam wilayah administrasi Kecamatan Koto XI Tarusan Kabupaten Pesisir Selatan Provinsi Sumatera Barat. Posisi 0.59' - 1.7'LS dan 100,34' 100.64' BT pada ketinggian 1-140 m dari permukaan laut, dengan luas wilayah sebagai berikut :

Tabel 2. Luas wilayah daratan dan perairan Pelabuhan PantaiCarocok Tarusan

\begin{tabular}{lllll}
\hline No & Wilayah & Satuan & Luas & Keterangan \\
\hline 1. & Daratan: & & & \\
& $\circ$ Status & Ha & 2,19 & \\
& HPL & Ha & 1,19 & \\
& Status & Ha & 2,19 & \\
& Hak & & & \\
& Pakai & & & \\
& Luas & & & \\
& daratan & & &
\end{tabular}

2. Perairan

Laut : $\quad$ Ha 30 perairan 8-

o Kolam Ha $30 \quad 10 \mathrm{~m}$ Pelabu han

Luas

Perairan

Total Luas W (Sumber : Pelabuhan Perikanan PantaiCarocok Tarusan)

Jarak Pelabuhan Perikanan PantaiCarocok Tarusandari pusat Kota Padang 63,1 km, dan dari Bandara Internasional Minangkabau 64,8 $\mathrm{km}$.

\section{Kondisi Topografi}

Secara Topografi kawasan daratan Pelabuhan Perikanan PantaiCarocok Tarusanumumnya datar,karena kawasan PantaiCarocok Tarusan merupakan tanah hasil reklamasi pantai dengan luas 2,19 Ha.

\section{Kondisi Dermaga Dari Segi Penyelenggaraan \\ Pelabuhan Perikanan PantaiCarocok} Tarusanmerupakan jenis pelabuhan umum. Pelabuhan yang diselenggarakan untuk kepentingan pelayanan masyarakat umum. Pelabuhan Perikanan PantaiCarocok Tarusanmelayani atau memberikan fasilitasfasilitas dermaga bongkar, gedung pelelangan ikan, los bongkar dan sebagainya.

Kondisi di Pelabuhan Perikanan PantaiCarocok Tarusan menunjukkan bahwa nelayan pergi ke laut pada jam yang hampir sama, sedangkan saat datang juga hampir bersamaan maka dermaga bongkar maupun muat dapat dijadikan satu.

\section{Kondisi Dermaga Dari Segi Penggunaan}

Dari segi penggunaannya Pelabuhan Perikanan PantaiCarocok Tarusan termasuk kedalam jenis pelabuhan ikan dengan kondisi kunjungan kapal ikan/perikanan ke Pelabuhan Perikanan Pantai Carocok Tarusan dari tahun 2014-2018 cenderung tidak mengalami penurunan seperti produksi perikanan dan cenderung mengalami penurunan. Jumlah kunjungan kapal tertinggi pada tahun 2014 sebanyak $8161 \mathrm{kapal} / \mathrm{tahun}$ dan pada tahun 2018 sebanyak 2312 kapal/tahun. Jumlah kunjungan kapal terbanyak yaitu kapal dengan ukuran <30 GT yaitu sejumlah 2328 unit dan kapal ukuran >30 GT sebanyak 5833a unit. 


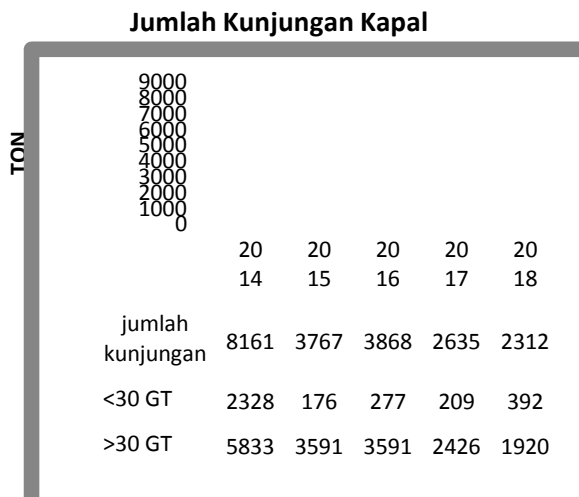

Gambar GrafikJumlah Kunjungan Kapal Pelabuhan Carocok Tarusan Tahun 2014-2018.

( Sumber : Pelabuhan Perikanan Carocok Tarusan )

Meningkatnya jumlah kunjungan juga diikuti peningkatan jumlah bongkar ikan di Pelabuhan Perikanan Carocok Tarusan. Pada tahun 2014 jumlah kapal yang membongkar ikan mencapai 1460 unit kapal.Pada tahun 2018 jumlah kapal yang membongkar ikan terjadi peningkatan mencapai 7186 unit (Tabel 4.4).

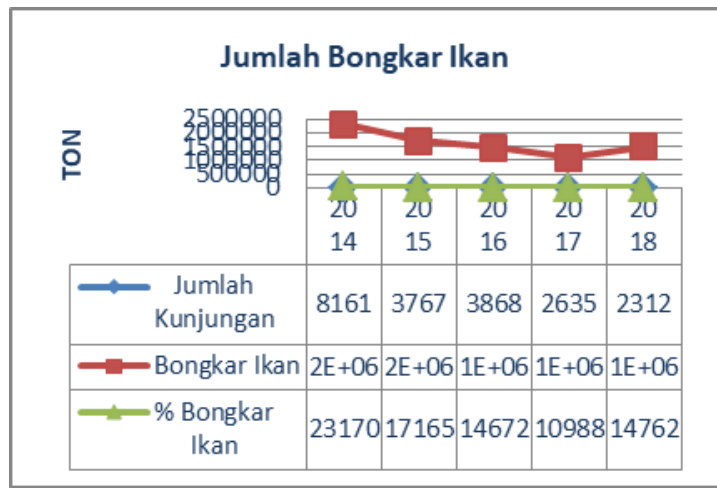

Gambar GrafikPerkembangan Jumlah Bongkar Ikan Pelabuhan Perikanan PantaiCarocok Tarusan Tahun 2013-2018.

( Sumber : Pelabuhan Perikanan Pantai Carocok Tarusan)

Keterangan : Jumlah kunjungan kapal $=$ Kapal $<30$ GT + Kapal >30 GT

\section{Tipe dan Ukuran Dermaga}

Tipe dermaga yang dipakai Pelabuhan Perikanan Pantai Carocok Tarusanini adalah tipe jetty atau pier. Masing-masing dermaga tersebut terdiri dari dermaga bongkar, dermaga muat dan dermaga tambat. Fasilitas dermaga yang ada sekarang sepanjang $100 \mathrm{~m}$.

\section{Jumlah Produksi Ikan}

Perkembangan jumlah produksi ikan di Pelabuhan Perikanan Pantai Carocok Tarusan mengalami pola penurunan sejak tahun 2015 sampai 2016. Produksi tahun 2017 mencapai $1.098,804$ ton/tahun. Produksi pada tahun 2018 hanya $1.476,155$ ton/tahun (tabel 4.5).

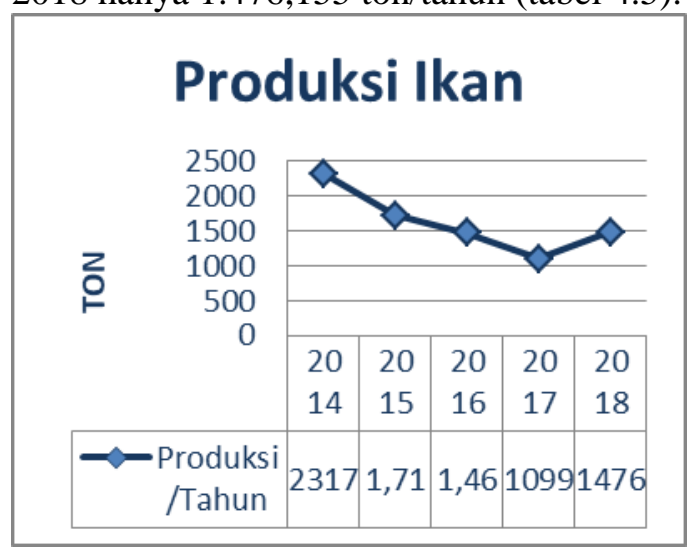

Gambar GrafikPerkembangan Jumlah Produsi Ikan Pelabuhan Perikanan PantaiCarocok

Tarusan Tahun 20014-2018.

( Sumber : Pelabuhan Perikanan PantaiCarocok Tarusan)

Dilihat dari data jenis ikan tangkapan, pada tahun 2013-2017 tidak terdapat perkembangan yang signifikan. Akan tetapi pada tahun 2015 mengalami kenaikan dan menurun kembali pada tahun berikutnya (tabel 4.5).

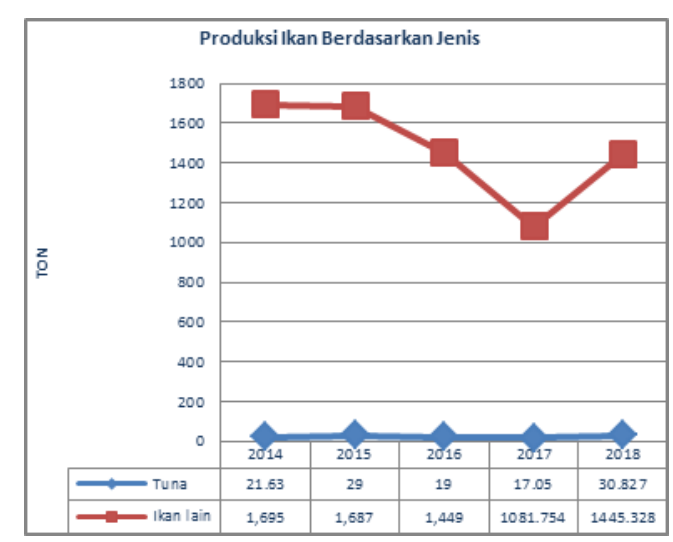

Gambar Grafik Perkembangan Jumlah

Produksi Ikan Berdasarkan Jenis

( Sumber : Pelabuhan Perikanan PantaiCarocok Tarusan)

Pada saat peninjauan lapangan dijumpai kapalkapal berukuran sedang $30 \mathrm{GT}$, lama trip ratarata 1 hari. Jarak daerah tangkapan terjauh rata-rata \pm 40 mil. Bila pengelolaan usaha perikanan dapat diatur secara optimal menurut 
jumlah unit kapal ikan yang akan mendaratkan ikan di Pelabuhan Perikanan PantaiCarocok Tarusan dengan jumlah kapal dan ukuran terbagi menjadi 6 kelompok kapal motor $0-5$ GT, 5-10 GT, 10-20 GT, 20-30 GT, 30-50 GT, 50-100 GT yang menjadi sasaran utama sebagai pelabuhan pantai, maka dapat ditabelkan secara hipotesis komposisi armada seperti table 3 tersebut :

Tabel 3. Estimasi Hipotesis Untuk Kapal dan Produksi yang Akan Didaratkan

\begin{tabular}{|c|c|c|c|c|c|}
\hline $\begin{array}{c}\text { Ukura } \\
\text { n / } \\
\text { Jenis } \\
\text { Kapal }\end{array}$ & $\begin{array}{c}\text { Ju } \\
\text { ml } \\
\text { ah } \\
\text { Un } \\
\text { it }\end{array}$ & $\begin{array}{c}\text { Lam } \\
\text { a } \\
\text { Trip }\end{array}$ & $\begin{array}{c}\text { Juml } \\
\text { ah } \\
\text { Trip/ } \\
\text { Tahu } \\
\text { n }\end{array}$ & $\begin{array}{l}\text { Ch } \\
\text { atc } \\
\text { h/t } \\
\text { rip }\end{array}$ & $\begin{array}{c}\text { Ju } \\
\text { mla } \\
\text { h } \\
\text { Pro } \\
\text { duk } \\
\text { si/T } \\
\text { ahu } \\
\text { n }\end{array}$ \\
\hline $\begin{array}{l}\mathrm{KM}<5 \\
\text { GT }\end{array}$ & 1 & $\begin{array}{c}1 \\
\text { hari }\end{array}$ & 12 & $\begin{array}{l}0,4 \\
\text { ton }\end{array}$ & $\begin{array}{c}4,45 \\
1 \\
\text { ton }\end{array}$ \\
\hline $\begin{array}{l}\text { KM 5- } \\
10 \text { GT }\end{array}$ & 17 & $\begin{array}{c}1 \\
\text { hari }\end{array}$ & 24 & $\begin{array}{l}0,2 \\
\text { ton }\end{array}$ & $\begin{array}{c}3,68 \\
6 \\
\text { ton }\end{array}$ \\
\hline $\begin{array}{l}\text { KM } \\
10- \\
20 G T \\
\end{array}$ & 25 & $\begin{array}{c}1 \\
\text { hari }\end{array}$ & 21 & $\begin{array}{l}1,4 \\
\text { ton }\end{array}$ & $\begin{array}{c}30,2 \\
64 \\
\text { ton } \\
\end{array}$ \\
\hline $\begin{array}{l}\text { KM } \\
20-30 \\
\text { GT }\end{array}$ & 52 & $\begin{array}{c}2 \\
\text { hari }\end{array}$ & 50 & $\begin{array}{l}9,5 \\
\text { ton }\end{array}$ & $\begin{array}{l}472, \\
647 \\
\text { ton }\end{array}$ \\
\hline $\begin{array}{l}\text { KM } \\
30-50 \\
\text { GT }\end{array}$ & 52 & $\begin{array}{c}2 \\
\text { hari }\end{array}$ & 5 & $\begin{array}{l}2,1 \\
\text { ton }\end{array}$ & $\begin{array}{c}10,4 \\
62 \\
\text { ton }\end{array}$ \\
\hline $\begin{array}{l}\text { KM } \\
50-100 \\
\text { GT }\end{array}$ & 5 & $\begin{array}{c}14 \\
\text { hari }\end{array}$ & 18 & $\begin{array}{c}24, \\
2 \\
\text { ton }\end{array}$ & $\begin{array}{l}434, \\
884 \\
\text { ton }\end{array}$ \\
\hline Jumlah & $\begin{array}{c}15 \\
2\end{array}$ & & 131 & & $\begin{array}{l}956, \\
394 \\
\text { ton }\end{array}$ \\
\hline
\end{tabular}

( Sumber : Pelabuhan Perikanan Pantai Carocok Tarusan)

Keterangan :

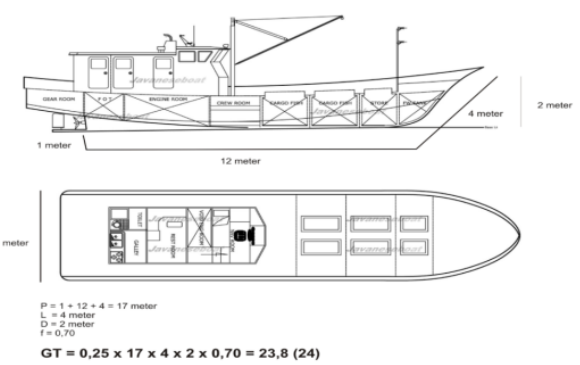

Chatch $=\frac{\text { Total produksi }(\mathrm{kg})}{\text { jumlah trip }}$

\section{Kondisi Tambat Laut}

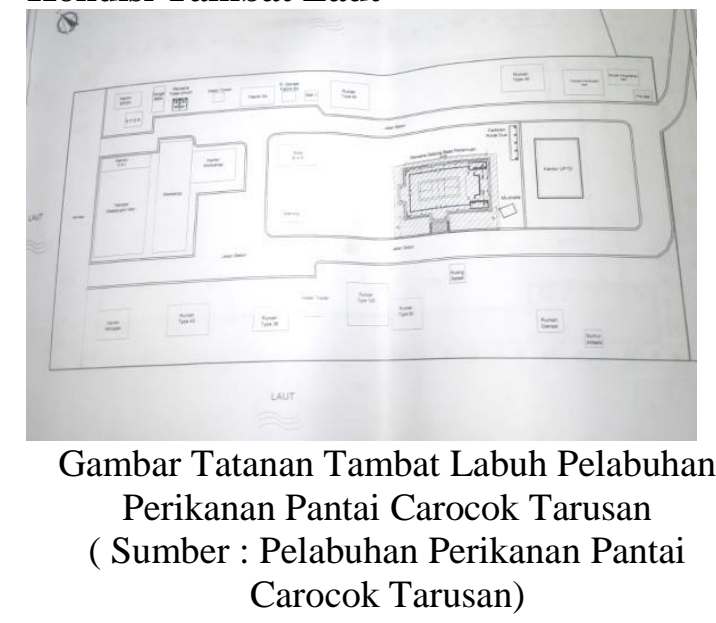

Kondisi tatanan tambat kapal di Pelabuhan Perikanan Pantai Carocok Tarusan terdapat 2 bentuk susunan tatanan tambat yaitu :

1. Tegak lurus terhadap dermaga.

2. Memanjang terhadap dermaga.

Tatanan tegak lurus terhadap dermaga terletak pada sisi ujung kanan dan kanan dan tatanan memanjang terletak pada sisi kanan dermaga.

\section{ANALISA}

\section{Kapasitas Dermaga}

Tabel 4. Jenis Kapal yang Akan Berlabuh di Pelabuhan Perikanan Pantai Carocok Tarusan.

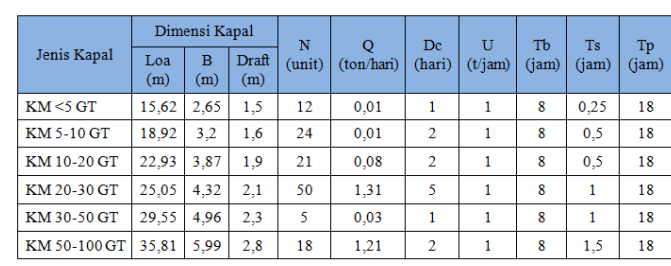

( Sumber : Pelabuhan Perikanan Pantai

Carocok Tarusan) 
Ket:

Loa $=$ Panjang kapal total $(\mathrm{m})$ Lenght Over All.

$\mathrm{Lu}=1,1$. Loa.

$\mathrm{n} \quad=$ Jumlah kapal yang beroperasi (unit).

$\mathrm{Q}=$ Hasil tangkapan rata-rata sekali pelayaran (ton).

Dc = Rata-rata periode ulang pelayaran (hari).

$\mathrm{U}=$ Kecepatan bongkar muat rata-rata termasuk persiapan (ton/jam).

$\mathrm{Tb}=$ Waktu yang diperlukan untuk pembongkaran per hari (jam).

$\mathrm{Ts}=$ Waktu pelayaran yang diperlukan per kapal.

$\mathrm{S}=$ Faktor ketidaktentuan.

Analisa Kapasitas Dermaga

a. Dermaga Bongkar Ikan

Panjang

$: 100 \mathrm{~m}$

Lebar

$: 8 \mathrm{~m}$

Kedalaman air disisi dermaga $\quad: 8 \mathrm{~m}$

b. Ukuran Kapal

Tabel5. Ukuran kapal yang Akan Berlabuh di Pelabuhan Perikanan Pantai Carocok Tarusan

\begin{tabular}{|l|c|c|c|}
\hline \multirow{2}{*}{ Jenis Kapal } & \multicolumn{3}{|c|}{ Dimensi Kapal } \\
\cline { 2 - 4 } & Loa (m) & B (m) & Draft (m) \\
\hline KM <5 GT & 15,62 & 2,65 & 1,5 \\
\hline KM 5-10 GT & 18,92 & 3,2 & 1,6 \\
\hline KM 10-20 GT & 22,93 & 3,87 & 1,9 \\
\hline KM 20-30 GT & 25,05 & 4,32 & 2,1 \\
\hline KM 30-50 GT & 29,55 & 4,96 & 2,3 \\
\hline KM 50-100 GT & 35,81 & 5,99 & 2,8 \\
\hline
\end{tabular}

( Sumber : Pelabuhan Perikanan Carocok

Tarusan )

Perhitungan panjang dermaga bongkar :

Panjang dermaga ditetapkan dengan rumus empiris, sebagai berikut.:

$$
\mathrm{Lb}=\frac{\mathrm{n} \cdot \mathrm{Lu} \cdot \mathrm{Q} \cdot \mathrm{s}}{\mathrm{De} \cdot \mathrm{U} \cdot \mathrm{Tb}}
$$

\section{$>\mathrm{KM}<5 \mathrm{GT}$ :}

$\mathrm{Lb}=\frac{\mathrm{n} \cdot \mathrm{Lu} \cdot \mathrm{Q} \cdot \mathrm{S}}{\mathrm{Dc} \cdot \mathrm{U} \cdot \mathrm{Tb}}$

$$
\begin{aligned}
& =\frac{1 \cdot 1,1 \cdot 15,62 \cdot 0,01 \cdot 1,5}{1 \cdot 1 \cdot 8} \\
& =0,48 \mathrm{~m}
\end{aligned}
$$

$$
\begin{array}{rl}
\mathrm{KM} & 10-20 \mathrm{GT} \\
\mathrm{Lb} & =\frac{\mathrm{n} \cdot \mathrm{Lu} \cdot \mathrm{Q} \cdot \mathrm{s}}{\mathrm{Dc} \cdot \mathrm{U} \cdot \mathrm{Tb}} \\
& =\frac{25 \cdot 1,1 \cdot 22,93 \cdot 0,08 \cdot 1,5}{2 \cdot 1 \cdot 8} \\
& =4,77 \mathrm{~m}
\end{array}
$$

KM 20-30 GT:

$\mathrm{Lb}=\frac{\mathrm{n} \cdot \mathrm{Lu} \cdot \mathrm{Q} \cdot \mathrm{S}}{\mathrm{Dc} \cdot \mathrm{U} \cdot \mathrm{Tb}}$

$=\frac{52 \cdot 1,1 \cdot 25,65 \cdot 1,31 \cdot 1_{2} 5}{5 \cdot 1 \cdot 8}$

$$
=70,55 \mathrm{~m}
$$

KM 30-50 GT:

$$
\begin{aligned}
\mathrm{Lb} & =\frac{\mathrm{n} \cdot \mathrm{Lu} \cdot \mathrm{Q} \cdot \mathrm{S}}{\mathrm{Dc} \cdot \mathrm{U} \cdot \mathrm{Tb}} \\
& =\frac{5 \cdot 2 \cdot 1,1 \cdot 29_{2} 55 \cdot 0,03 \cdot 1,5}{1 \cdot 1 \cdot 8} \\
& =9,21 \mathrm{~m}
\end{aligned}
$$

$$
\begin{aligned}
& \text { KM 50-100 GT: } \\
& \begin{aligned}
\text { Lb } & =\frac{\text { n. Lu. Q. S }}{\text { De } \cdot \mathrm{U} \cdot \mathrm{Tb}} \\
& =\frac{5 \cdot 1,1 \cdot 35,81 \cdot 1,21 \cdot 1,5}{2 \cdot 1 \cdot 8} \\
& =107,07 \mathrm{~m}
\end{aligned}
\end{aligned}
$$

Perhitungan panjang dermaga muat :

Panjang dermaga ditetapkan dengan rumus empiris, sebagai berikut.:

$$
\begin{aligned}
& \mathrm{Lm}=\frac{\mathrm{n} \cdot \mathrm{Lu} \cdot \mathrm{Ts} \cdot \mathrm{S}}{\mathrm{Dc} \cdot \mathrm{Tp}} \\
& \mathrm{Lm}=\frac{\mathrm{n} \cdot \mathrm{Lu} \cdot \mathrm{Ts} \cdot \mathrm{s}}{\mathrm{De} \cdot \mathrm{Tp}} \\
& =\frac{1 \cdot 1,1 \cdot 15,62 \cdot 0,25 \cdot 1,2}{1 \cdot 18} \\
& =3,44 \mathrm{~m}
\end{aligned}
$$

KM 5-10 GT:

$$
\begin{aligned}
\mathrm{Lm} & =\frac{\mathrm{n} \cdot \mathrm{Lu} \cdot \mathrm{Ts} \cdot \mathrm{S}}{\mathrm{Dc} \cdot \mathrm{Tp}} \\
& =\frac{17 \cdot 1,1 \cdot 18,92 \cdot 0,50 \cdot 1,2}{2 \cdot 18} \\
& =8,32 \mathrm{~m}
\end{aligned}
$$

KM 10-20 GT:

$$
\begin{aligned}
\mathrm{Lm} & =\frac{\mathrm{n} \cdot \mathrm{Lu} \cdot \mathrm{Ts} \cdot \mathrm{S}}{\mathrm{Dc} \cdot \mathrm{Tp}} \\
& =\frac{25 \cdot 1,1 \cdot 22,93 \cdot 0,50 \cdot 1,2}{2 \cdot 18} \\
& =10,09 \mathrm{~m}
\end{aligned}
$$


KM 20-30 GT:

$$
\begin{aligned}
\mathrm{Lm} & =\frac{\mathrm{n} \cdot \mathrm{Lu} \cdot \mathrm{Ts} \cdot \mathrm{S}}{\mathrm{Dc} \cdot \mathrm{Tp}} \\
& =\frac{52 \cdot 1,1 \cdot 25,05 \cdot 1 \cdot 1,2}{5 \cdot 18} \\
& =19,10 \mathrm{~m}
\end{aligned}
$$

KM 30-50 GT:

$$
\begin{aligned}
\text { Lm } & =\frac{\text { n. Lu. Ts } \cdot S}{\text { De } \cdot \mathrm{Tp}} \\
& =\frac{52 \cdot 1,1 \cdot 29,55 \cdot 1 \cdot 1,2}{1 \cdot 18} \\
& =112,68 \mathrm{~m}
\end{aligned}
$$

$>$ KM 50-100 GT:

$$
\begin{aligned}
\mathrm{Lm} & =\frac{\mathrm{n} \cdot \mathrm{Lu} \cdot \mathrm{Ts} \cdot \mathrm{s}}{\mathrm{De} \cdot \mathrm{Tp}} \\
& =\frac{5 \cdot 1,1 \cdot 35,81 \cdot 1,5 \cdot 1,2}{2 \cdot 18} \\
& =47,27 \mathrm{~m}
\end{aligned}
$$

Tabel:Kebutuhan panjang dermaga untuk bongkar dan muat kapal di Pelabuhan Perikanan Pantai Carocok Tarusan.

\begin{tabular}{|l|c|c|c|c|c|c|c|}
\hline \multirow{2}{*}{ Jenis Kapal } & \multicolumn{3}{|c|}{ Dimensi Kapal } & \multicolumn{2}{c|}{ Bongkar } & \multicolumn{2}{c|}{ Muat } \\
\cline { 2 - 8 } & Loa (m) & B (m) & Draft (m) & S & Lb & S & Lm \\
\hline KM <5 GT & 15,62 & 2,65 & 1,5 & 1,5 & 0,48 & 1,2 & 3,44 \\
\hline KM 5-10 GT & 18,92 & 3,2 & 1,6 & 1,5 & 0,48 & 1,2 & 8,32 \\
\hline KM 10-20 GT & 22,93 & 3,87 & 1,9 & 1,5 & 4,77 & 1,2 & 10,09 \\
\hline KM 20-30 GT & 25,05 & 4,32 & 2,1 & 1,5 & 70,55 & 1,2 & 19,10 \\
\hline KM 30-50 GT & 29,55 & 4,96 & 2,3 & 1,5 & 9,21 & 1,2 & 112,68 \\
\hline KM 50-100 GT & 35,81 & 5,99 & 2,8 & 1,5 & 107,07 & 1,2 & 47,27 \\
\hline
\end{tabular}

( Sumber : Hasil Analisis )

Jadi kebutuhan panjang dermaga untuk bongkar dan muat

Tabel :Rekapitulasi kebutuhan panjang dermaga untuk bongkar dan muat di Pelabuhan Perikanan Pantai Carocok Tarusan.

\begin{tabular}{|c|c|c|c|}
\hline Kelompok & Bongkar & Muat & $\begin{array}{c}\text { Kedala- } \\
\text { man } \\
\text { Kolam }\end{array}$ \\
\hline $\begin{array}{c}\text { KM <30 } \\
\text { GT }\end{array}$ & 76,27 & 40,96 & -8 \\
\hline $\begin{array}{c}\text { KM >30 } \\
\text { GT }\end{array}$ & 116,28 & 159,95 & -8 \\
\hline
\end{tabular}

( Sumber : Hasil Analisis )

\section{a. Bongkar}

$$
\begin{aligned}
& \mathrm{KM}<30 \mathrm{GT}=\mathrm{KM}<5 \mathrm{GT}+\mathrm{KM} 5-10 \mathrm{GT}+ \\
& \mathrm{KM} 10-20 \mathrm{GT}+\mathrm{KM} 20-30 \mathrm{GT} \\
& \quad=0,48+0,48+4,77+70,55
\end{aligned}
$$

$$
=76,27
$$

$$
\begin{aligned}
& \mathrm{KM}>30 \mathrm{GT}=\mathrm{KM} 20-30 \mathrm{GT}+\mathrm{KM} 30-50 \\
& \text { GT + KM 50-100 GT } \\
& =70,55+9,21+107,07=11,28 \\
& \mathrm{KM}<30 \mathrm{GT}=\mathrm{KM}<5 \mathrm{GT}+\mathrm{KM} 5-10 \mathrm{GT}+ \\
& \text { KM 10-20 GT + KM } 20 \text { - 30GT } \\
& \begin{array}{l}
=3,44+8,32+10,10+19,10 \\
=40,96
\end{array}
\end{aligned}
$$

$\mathrm{KM}>30 \mathrm{GT}=\mathrm{KM}$ 20-30 GT $+\mathrm{KM} 30-50$ GT + KM 50-100 GT

$$
\begin{aligned}
& =19,10+112,68+47,27= \\
& 159,95
\end{aligned}
$$

Karena Loa kapal terbesar 35,81 m, maka panjang dermaga untuk Pelabuhan Perikanan Pantai Carocok Tarusan untuk bongkar kapal : $116,28 \mathrm{~m} \sim 120 \mathrm{~m}$ dan untuk muat kapal : $159,95 \mathrm{~m} \sim 160 \mathrm{~m}$.

Panjang dermaga Pelabuhan Perikanan Pantai Carocok Tarusan sekarang adalah $100 \mathrm{~m}$ $100 \mathrm{~m}<160 \mathrm{~m}$ ...NO

Berarti Panjang Dermaga Pelabuhan Perikanan Pantai Carocok Tarusan harus di tambah $60 \mathrm{~m}$

\section{Kapasitas Kolam Pelabuhan}

Kapasitas kolam pelabuhan Rumus turning basin yaitu :

Lebarr $=$ Loa $+20 \%$. Loa

Berat: <30 GT

Panjang (Loa): 25,05 m

$\mathrm{r}=1+20 \% .1$

$=25,05 \mathrm{~m}+20 \% \cdot 25,05 \mathrm{~m}$

$=30,06 \mathrm{~m}^{2}$

$$
\begin{aligned}
& \text { Berat } \quad:>30 \mathrm{GT} \\
& \begin{aligned}
\text { Panjang (Loa) } & : 35,81 \mathrm{~m} \\
\mathrm{r}=1+20 \% .1 & \\
& =35,81 \mathrm{~m}+20 \% \cdot 35,81 \mathrm{~m} \\
& =42,97 \mathrm{~m}^{2}
\end{aligned}
\end{aligned}
$$

Lebar

$$
\begin{aligned}
& r=30,06+42,97 \\
& =73,03 \mathrm{~m}^{2}
\end{aligned}
$$

Luas $\mathrm{Ltb}=\pi \cdot \mathrm{r}^{2}$

$$
\begin{aligned}
& =3,14 \cdot 73,03^{2} \\
& =16 \cdot 746,81 \mathrm{~m}^{2}
\end{aligned}
$$


$\mathrm{L}=\mathrm{Ltb}+(3 . \mathrm{n} .1 . \mathrm{B})$

$=16.746+[(3.95 \cdot 25,05.4,32)$

$+(3.57 .43,39.7,23)]$

$=16.746+[(30.841,56$

$+53.644,3587)]$

$=86.232,72 \mathrm{~m}^{2}$

Luas kolam Pelabuhan Pantai Carocok Tarusan yaitu $86.232,72 \mathrm{~m}^{2}$, perlu penambahan sebesar $56.232,72 \mathrm{~m}^{2}$ pada perhitungan kebutuhan kolam pada saat beban maksimum. Panjang dermaga bongkar yang telah ada sekarang yaitu $100 \mathrm{~m}$ belum sesuai dengan kapasitas yang dibutuhkan untuk bongkar muat kapal di Pelabuhan Perikanan Pantai Carocok Tarusan.

Volume Bongkar Muat

Tabel : Volume Produksi Ikan yang didaratkan Selama Tahun 2018.

\begin{tabular}{|c|l|c|c|}
\hline \multirow{2}{*}{ No. } & \multirow{2}{*}{ Bulan } & $\mathbf{2}$ Volume (Kg) \\
\cline { 3 - 4 } & & $\begin{array}{c}\text { Rata- } \\
\text { rata } \\
\text { Per Hari }\end{array}$ \\
\hline 1. & Januari & 46.750 & 1508,06 \\
\hline 2. & Februari & 38.515 & 1375,54 \\
\hline 3. & Maret & 113.219 & 3652,23 \\
\hline 4. & April & 174.944 & 5831,47 \\
\hline 5. & Mei & 182.164 & 5876,26 \\
\hline 6. & Juni & 61.465 & 2048,83 \\
\hline 7. & Juli & 57.106 & 1842,13 \\
\hline 8. & Agustus & 111.452 & 3595,23 \\
\hline 9. & September & 163.018 & 5433,93 \\
\hline 10. & Oktober & 110.280 & 3557,42 \\
\hline 11. & November & 281.989 & 9399,63 \\
\hline 12. & Desember & 135.253 & 4363,00 \\
\hline \multicolumn{2}{|c|}{ JUMLAH } & 1.4761 .155 & $40.441,52$ \\
\hline
\end{tabular}

( Sumber : Hasil Analisis )

Rata-rata volume ikan perhari selama 1 tahun

$$
\begin{aligned}
& =\frac{\sum \text { rata }- \text { rata volume ikan }}{\sum \text { hari setahun }} \\
& =\frac{14.761 .155}{365} \\
& =40.441,52 \mathrm{Kg} / \text { hari } \\
& \sim 40,441 \text { ton } / \text { hari }
\end{aligned}
$$

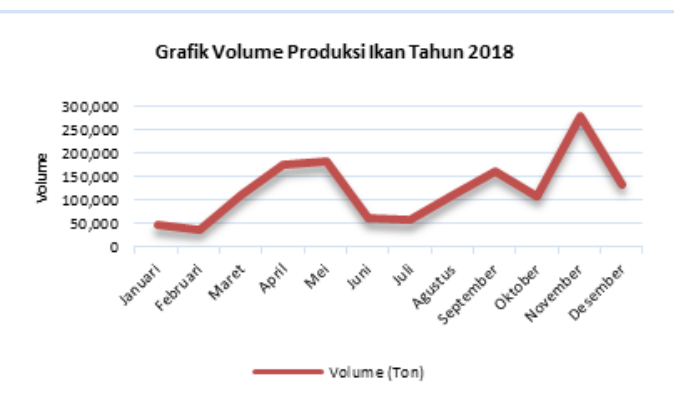

Gambar Grafik Volume Produksi Ikan yang didaratkan Selama Tahun 2018

( Sumber : Hasil Analisis )

Lama waktu bongkar muat rata-rata perhari

$$
\begin{aligned}
& =\frac{\text { rata-rata produksi ikan/hari }}{\text { waktu bongkar muat }} \\
& =\frac{40,44 \mathrm{ton}}{4,75 \mathrm{ton} / \mathrm{jam}} \\
& =8,51 \mathrm{jam}
\end{aligned}
$$

\section{Tingkat Jumlah Kedatangan Kapal}

Tabel Jumlah Kedatangan Kapal di Pelabuhan Perikanan Pantai Carocok Tarusan Tahun 2018

\begin{tabular}{|c|l|c|c|}
\hline \multirow{2}{*}{ No. } & \multirow{2}{*}{ Bulan } & \multicolumn{2}{|c|}{$\begin{array}{c}\text { Jumlah Kapal } \\
\text { (Unit) }\end{array}$} \\
\cline { 3 - 4 } & & $\mathbf{2 0 1 8}$ & $\begin{array}{c}\text { Rata- } \\
\text { rata } \\
\text { Per Hari }\end{array}$ \\
\hline 1. & Januari & 127 & 4,10 \\
\hline 2. & Februari & 129 & 4,61 \\
\hline 3. & Maret & 153 & 4,94 \\
\hline 4. & April & 184 & 6,13 \\
\hline 5. & Mei & 210 & 6,77 \\
\hline 6. & Juni & 93 & 3,10 \\
\hline 7. & Juli & 244 & 7,87 \\
\hline 8. & Agustus & 352 & 11,35 \\
\hline 9. & September & 173 & 5,77 \\
\hline 10. & Oktober & 203 & 6,55 \\
\hline 11. & November & 244 & 8,13 \\
\hline 12. & Desember & 200 & 6,45 \\
\hline \multicolumn{2}{|c|}{ JUMLAH } & 2.312 & 75,77 \\
\hline
\end{tabular}

( Sumber : Hasil Analisis )

Rata-rata setiap hari dalam 1 tahun

$$
\begin{aligned}
& =\frac{\sum \text { rata }- \text { rata kapal } / \text { hari }}{\sum \text { bulan setahun }} \\
& =\frac{75_{2}, 77}{12}=6,31 \mathrm{kapal} / \mathrm{hari}
\end{aligned}
$$

Jadi tahun 2018 rata-rata jumlah kapal yang datang ke Pelabuhan Perikanan Pantai 
Carocok Tarusan setiap hari adalah 6,31 unit kapal.

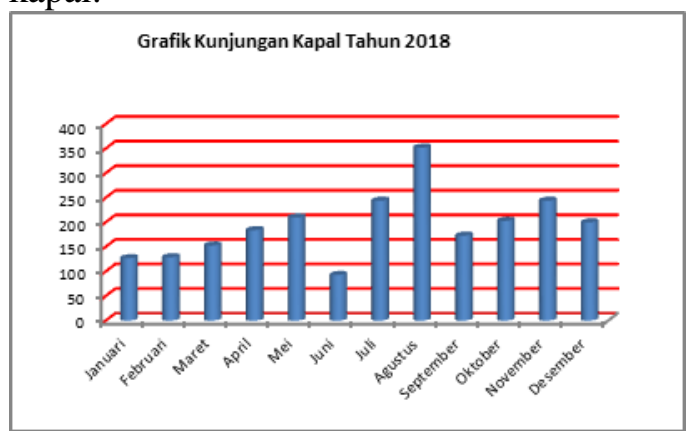

Gambar Grafik Jumlah Kunjungan Kapal Tahun 2018

( Sumber : Hasil Analisis )

\section{Estimasi Jumlah Produksi Ikan dan Kunjungan Kapal}

Tabel :Jumlah Kunjungan Kapal Ikan Setiap Bulan di Pelabuhan Pantai Carocok Tarusan Tahun 2018-2025 dengan Asumsi Pertumbuhan $5 \%$ per Tahun

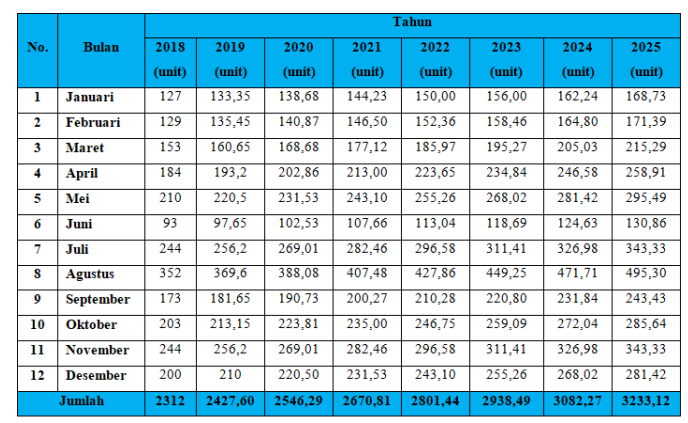

( Sumber : Hasil Analisis )

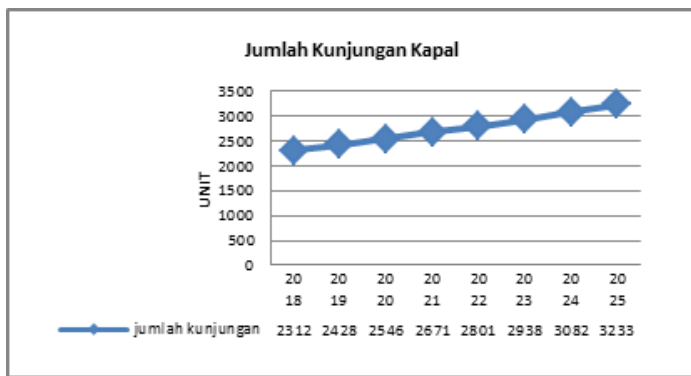

Gambar Grafik Estimasi Jumlah Kunjungan Kapal Tahun 2018- 2025

( Sumber : Hasil Analisis )

Dengan menggunakan asumsi pertumbuhan 5\% per tahun dari data kunjungan kapal ke Pelabuhan Perikanan Pantai Carocok Tarusan tahun 2018 dapat di perhitungkan jumlah kunjungan kapal periode 2018-2025 dalam kurun waktu 7 tahun ke depan.
Tabel :Jumlah Produksi Ikan Setiap Bulan di Pelabuhan Perikanan Pantai Carocok Tarusan Tahun 2018-2025 dengan Asumsi Pertumbuhan 5\% per Tahun.

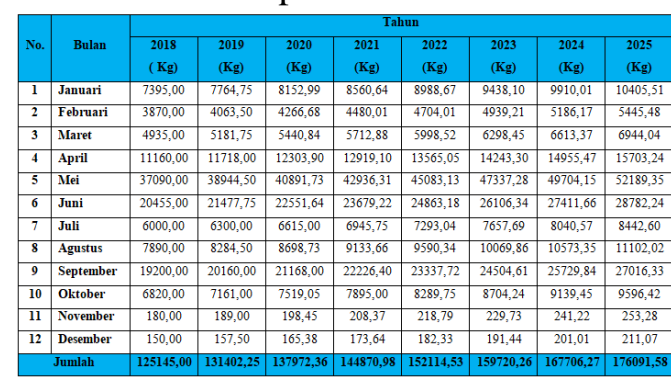

( Sumber : Hasil Analisis )

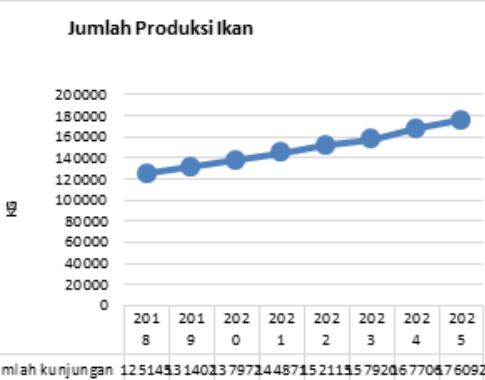

Gambar Grafik Estimasi Jumlah Produksi Ikan Tahun 2018- 2025

( Sumber : Hasil Analisis )

Dengan menggunakan asumsi pertumbuhan $5 \%$ per tahun dari data produksi ikan ke Pelabuhan Perikanan Pantai Carocok Tarusan tahun 2018 dapat diperhitungkan jumlah produksi ikan periode 2018-2025 dalam kurun waktu 7 tahun ke depan.

Rata-rata setiap hari produksi ikan tahun 2025

$$
\begin{aligned}
& =\frac{\sum \text { estimasi produksi ikan } 2025}{\sum \text { hari setahun }} \\
& =\frac{176,09}{360} \\
& =0,489 \text { ton } / \text { hari }
\end{aligned}
$$

Maka dari data estimasi jumlah kunjungan kapal yang diperoleh dapat direncanakan panjang kapasitas dermaga tahun 2025 yaitu :

Rata-rata setiap bulan jumlah kapal dalam 1 tahun

$$
\begin{aligned}
& =\frac{\sum \text { jumlah kapal tahun } 2025}{\sum \text { bulan setahun }} \\
& =\frac{3233_{i} 12}{12}=269,43 \mathrm{kapal}
\end{aligned}
$$

Jadi estimasi rata-rata jumlah kapal dalam 1 bulan tahun 2025 berjumlah 269,43 kapal. Maka dari data estimasi jumlah 
kunjungan kapal yang diperoleh dapat direncanakan estimasi panjang kapasitas dermaga tahun 2025 yaitu :

$\mathrm{L}=\frac{\mathrm{n} \cdot \mathrm{Lu} \cdot \mathrm{Q} \cdot \mathrm{S}}{\mathrm{De} \cdot \mathrm{U} \cdot \mathrm{Tb}}$

$$
\begin{aligned}
& =\frac{269,43 \cdot 1,1 \cdot 15,62 \cdot 0,489 \cdot 1,5}{1 \cdot 1 \cdot 8} \\
& =424,453 \mathrm{~m} \sim 425 \mathrm{~m}
\end{aligned}
$$

Jadi untuk 5 tahun kedepan Pelabuhan Perikanan Carocok Tarusan harus menambah panjang dermaga sepanjang $425 \mathrm{~m}$.

\section{PENUTUP}

\section{Simpulan}

1. Kebutuhan panjang dermaga Pelabuhan Perikanan Pantai Carocok Tarusan untuk melakukan bongkar dan muat ikan belum mencukupi dengan total panjang $100 \mathrm{~m}$ sedangkan yang dibutuhkan untuk bongkar dan muat kapal ikan sebesar 160 $m$ pada tahun 2018, jadi perlu penambahan $60 \mathrm{~m}$

2. Dalam periode Januari s/d Desember tahun 2018 jumlah kunjungan kapal untuk kegiatan pendaratan ikan di Pelabuhan Perikanan Pantai Carocok Tarusansebanyak 2.312 kapal sedangkan periode 5 tahun sebelumnya Januari s/d Desember tahun 2013 sebanyak 5.825 kapal, berarti dalam periode 5 tahun terjadi penurunan kunjungan kapal sebanyak 3.513 kapal.

3. Luas lahan Pelabuhan Perikanan Pantai Carocok Tarusan yaitu 2,19 Ha, sedangkan menurut Peraturan Menteri KP No.16 Tahun 2004 tentan persyaratan Pelabuhan Perikanan Pantai (PPP) luas Lahan 5 -15 Ha.

4. Luas kolam Pelabuhan Pelabuhan Perikanan Pantai Carocok Tarusanyaitu $30 \mathrm{Ha}$, sedangkan pada perhitungan kebutuhan kolam saat beban maksimum yaitu sebesar $86.232,72 \mathrm{~m}^{2}$ atau 86,232 Ha. Perlu penambahan ukuran luas kolam Pelabuhan Perikanan Pantai Carocok Tarusan minimal sebesar 56,232 Ha.

5. Pada sistem antrian kapal waktu layanan yang dapat dilayani adalah 8 jam untuk bongkar muat. Tingkat kedatangan kapal per tahun pada tahun 2018 berjumlah 2.312 kapal. Sedangkan tingkat kedatangan perhari berjumlah 6,31 kapal, jadi untuk pembongkaran muat ikan belum sesuai dengan kapasitas dermaga yang tersedia di Pelabuhan Perikanan Pantai Carocok Tarusan.

6. Dengan estimasi pertumbuhan produksi dan kedatangan kapal di Pelabuhan Perikanan Pantai Carocok Tarusan 5\% per tahun, untuk 7 tahun kedepan produksi ikan di Pelabuhan Perikanan Pantai Carocok Tarusan diperkirakan 176.091,58 ton/tahun dan kunjungan kapal sebanyak 3.233,12 kapal/tahun dengan kebutuhan panjang dermaga $4.25,453 \mathrm{~m}$.

\section{Saran}

1. Diperlukan penambahan luas kolam Pelabuhan Perikananan Pantai Carocok Tarusan sebesar 56,232 Ha, agar sistem operasional di Pelabuhan Perikanan Pantai Carocok Tarusan terpenuhi.

2. Untuk memenuhi syarat pelabuhan menurut Peraturan Menteri KP NO 16 Tahun 2004 perlu penambahan lahan Pelabuah Pantai Carocok Tarusan sebesar 3- 13 Ha agar termasuk karekteristik Pelabuhan Perikanan Pantai (PPP)

3. Perlu Penambahan Panjang dermaga Pelabuhan Pantai Carocok Tarusan sebesar $60 \mathrm{~m}$, agar dapat melayani proses bongkar muat kapal.

4. Perlunya peningkatan pelayanan dan fasilitas untuk kapal yang berkunjung ke dermaga Pelabuhan Perikanan Pantai Carocok Tarusan agar tingkat kedatangan kapal tidak menurun pada periode tahun berikutnya.

\section{DAFTAR PUSTAKA}

1. Baheramsyah,(2012). Kementrian Kelautan Dan Perikanan soroti Perkembangan Perikanan

2. Irawadi,Surya, (2010). Evaluasi Kapasitas Dermaga Pelabuhan Perikanan Samudera Bungus Padang.

3. Triadmodjo, Bambang, (1996). Pelabuhan. Yogyakarta : Penerbit Beta Offset.

4. Kramadibrata, Soedjona, (1985). Perencanaan Pelabuhan. Bandung : Penerbit Ganesha Excat.

5. Marnilawati, Ade, (2007). Tinjauan Aspek Operasional Pelabuhan Kapal Ikan di Pelabuhan Perikanan. 
6. Sagisolo, Jembris, (2014). Analisis Tingkat Pelayanan Dermaga Pelabuhan Sorong.

7. Peraturan Menteri No.16 (2004). Perasyatan Pelabuhan Perikanan Pantai.

8. Peraturan Presiden No.26 (2012). Tentan pengembangan sistem logistik nasional serta mengujudkan Program Peningkatan Kehidupan Nelayan ( PKN ).

9. PT. Syntac Pratama, (2007). Study Penataan Lingkungan Pelabuhan Perikanan Samudera Bungus Padang.

10. Keputusan Menteri Kelautan Dan Perikanan No.65 (2018). Penetapan Pelabuhan Perikanan Pantai Carocok Tarusan sebagai pankalan pendaratan ikan 